\title{
Cryopreserved fat: our clinical experience and applications
}

\author{
Masanori Ohashi \\ The Clinic Tokyo, Minato-ku, Tokyo 106-0031, Japan. \\ Correspondence to: Dr. Masanori Ohashi, The Clinic Tokyo, Nishiazabu 3-16-23 Minato-ku, Tokyo 106-0031, Japan. \\ E-mail: ohashi@theclinic.jp
}

How to cite this article: Ohashi M. Cryopreserved fat: our clinical experience and applications. Plast Aesthet Res 2020;7:26. http://dx.doi.org/10.20517/2347-9264.2020.15

Received: 29 Jan 2020 First Decision: 25 Mar 2020 Revised: 27 Apr 2020 Accepted: 7 May 2020 Published: 23 May 2020

Science Editor: Jian-Xing Song Copy Editor: Jing-Wen Zhang Production Editor: Jing Yu

\begin{abstract}
Aim: Cryopreservation of fat is an effective method for repeat fat grafting, but there are few reports about the clinical use of cryopreserved fat. The aim of this study was to determine the effectiveness and safety of cryopreserved fat for clinical use.
\end{abstract}

Methods: Between Aug 2015 and Dec 2018, we investigated 590 patients who underwent fat harvesting at our clinic. The harvested fat was cryopreserved at a temperature of $-196^{\circ} \mathrm{C}$ at a cell processing center and injections were performed in our clinic.

Results: Of the 590 patients studied, 216 (312 cases) have undergone fat injections so far. Volume augmentations using harvested fat, such as facial and breast augmentations, were performed on 180 patients. For 84 patients, harvested fat was utilized only for revitalization/fertilization purposes, such as to improve skin condition. There were no severe complications in any patients. However, volume maintenance was rarely observed. Skin rejuvenation effects were comparable to that in cases using fresh fat.

Conclusion: The clinical use of cryopreserved fat is thought to be safe and effective.

Keywords: Cryopreserved fat, frozen fat, fat grafting, skin rejuvenation 


\section{INTRODUCTION}

Fat grafting is used worldwide for volume augmentation. Recently, it has become clear that fat grafting has a regenerative effect (revitalization/fertilization) which leads to rejuvenation ${ }^{[1-6]}$.

However, one of the biggest problems of fat grafting is the unpredictable retention rate for volume augmentation. Additionally, skin rejuvenation effects vary ${ }^{[7]}$. Injections must often be repeated to achieve the targeted results ${ }^{[7-10]}$.

Another problem associated with fat grafting is the painful process of harvesting fat, which is also timeconsuming for both patients and doctors. Accordingly, it would be advantageous to both patients and plastic/aesthetic surgeons if fat could be harvested during one procedure and cryopreserved for later use.

The cryopreservation method has been researched for a long time, and many doctors conclude that the use of cryopreserved fat is useful and safe when appropriate methods are used ${ }^{[11-13]}$. However, most of these studies are experimental, and documented clinical use of such fat is scarce ${ }^{[14,15]}$.

The aim of this study was to determine the safety and benefits of the clinical use of cryopreserved fat.

\section{METHODS}

\section{Patients and methods}

Patients: Table 1.

From Aug 2015 to Dec 2018, we harvested fat from 490 patients and sent it to a cell processing center (CPC) (CellSource Co., Ltd., Tokyo, Japan) for cryopreservation at $-196^{\circ} \mathrm{C}$.

\section{Flowchart of harvesting, cryopreserving, and repeat injection}

At our clinic, we harvest patients' fat for same-day use. The residual fat is sent to the CPC. The CPC (CellSource Co.) cryopreserves the fat using their own cryoprotective agent at $-196{ }^{\circ} \mathrm{C}$. The company will then send back the thawed fat to our clinic for repeat injections [Figure 1].

\section{Anesthesia}

Usually, we use a combination of local anesthesia with tumescent technique and intravenous anesthesia.

\section{Harvest in the clinic}

When harvesting the patients' fat, we use a tumescent technique $(20 \mathrm{~mL}$ of $8.4 \%$ sodium hydrogen carbonate, $1 \mathrm{~mL}$ of epinephrine, and $50 \mathrm{~mL}$ of $1.0 \%$ lidocaine per $1000 \mathrm{~mL}$ of saline) with suction pressure of less than $1 \mathrm{~atm}$.

\section{Choice of donor site}

Fat is typically harvested from the thighs, lower abdomen, and flanks (so-called LFD: localized fat deposit) ${ }^{[17]}$, because these areas bleed the least and are the easiest sites from which to harvest fat.

\section{First injection at the clinic}

We usually inject the fat on the same day it is harvested. Fat grafting is used not only for volume augmentation but also for regenerative effects such as skin rejuvenation. When we use the fat for volume augmentation, we apply the so-called "Coleman technique", and for skin rejuvenation, we use the nanofat or squeezed fat technique ${ }^{[5,6]}$. 
Table 1. Characteristics of patients who had their fat cryopreserved $(n=490)$

\begin{tabular}{ll}
\hline Duration & Aug 2015 Dec 2018 \\
Sex & Male 26 Female 464 \\
Age (years) & $19-81(40.9 \pm 11.6)$ \\
Height $(\mathrm{cm})$ & $142-188(160.0 \pm 5.8)$ \\
Weight $(\mathrm{kg})$ & $37.6-90.7(52.1 \pm 8.0)$ \\
Body mass index $\left(\mathrm{kg} / \mathrm{m}^{2}\right)$ & $15.0-33.5(20.3 \pm 2.5)$ \\
\hline
\end{tabular}

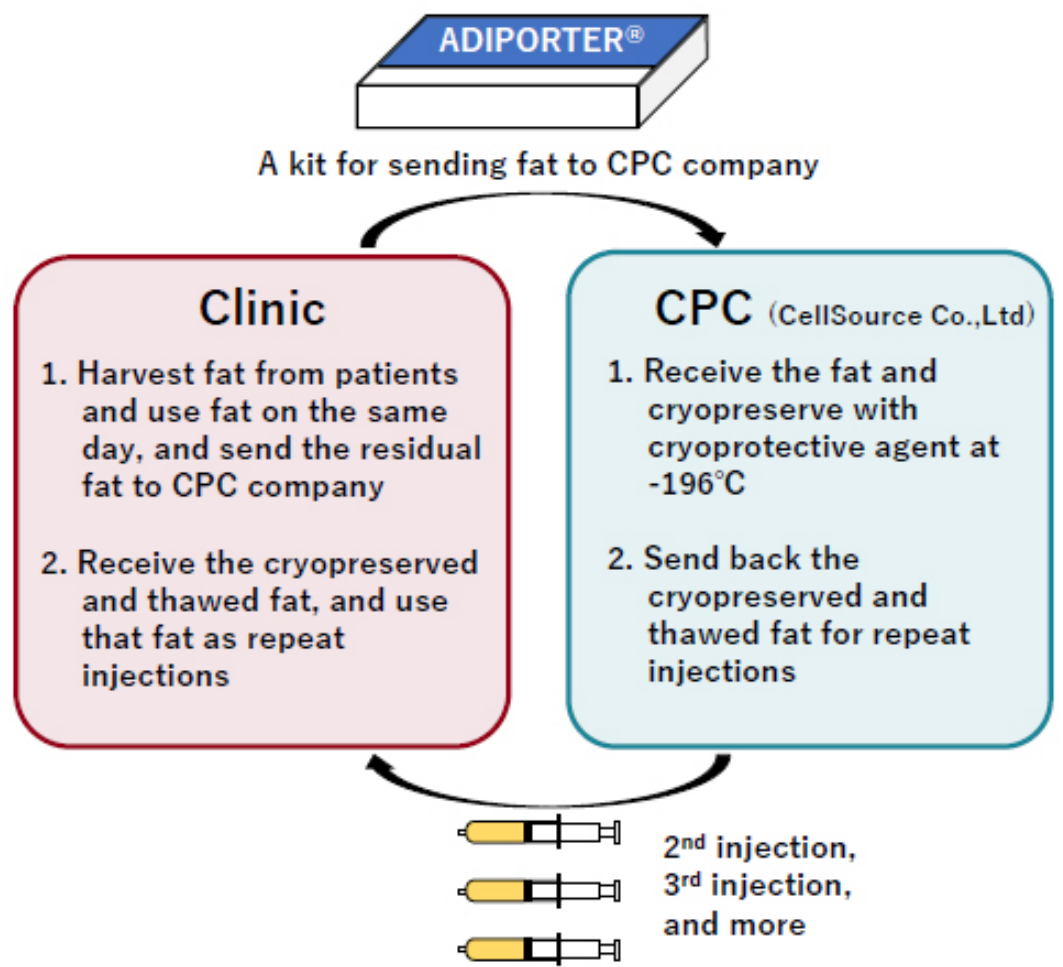

Figure 1. Flowchart of cryopreservation and fat grafting. This figure is used with permission from Ohashi published in Clin Plast Surg ${ }^{[16]}$

The main injection sites for volume augmentation are the breasts and the face (such as the forehead and cheeks). For skin rejuvenation, the main injection sites are the lower eyelids, the area surrounding the lips, and areas with signs of facial aging, e.g., wrinkles. Sometimes fat grafting is used for scar treatment such as in cases of double eyelids, liposuction revision, or contracture release in percutaneous aponeurotomy (socalled rigottomy).

\section{How to send the fat}

After fat is utilized on the day of harvest, the remaining fat is collected in a bag (FB-bag: CellSource Co.) which is then packed in an ADIPORTER box (CellSource Co., Ltd., Tokyo, Japan). After packing, the bag is sent to the CPC at CellSource Co. in a refrigerated state (below $10^{\circ} \mathrm{C}$ ) [Figure 2].

\section{Cryopreservation and storage of fat}

The process of cryopreservation and storage at $-196{ }^{\circ} \mathrm{C}$ was performed in the $\mathrm{CPC}$ at CellSource Co.

The details of this process are confidential matters for the company. Roughly speaking, delivered fat is washed using Ringer's lactate solution. The fat is mixed with a cryoprotectant and divided into 4- to 5-mL aliquots in syringes. These syringes are gradually frozen at a controlled rate until the temperature reaches 

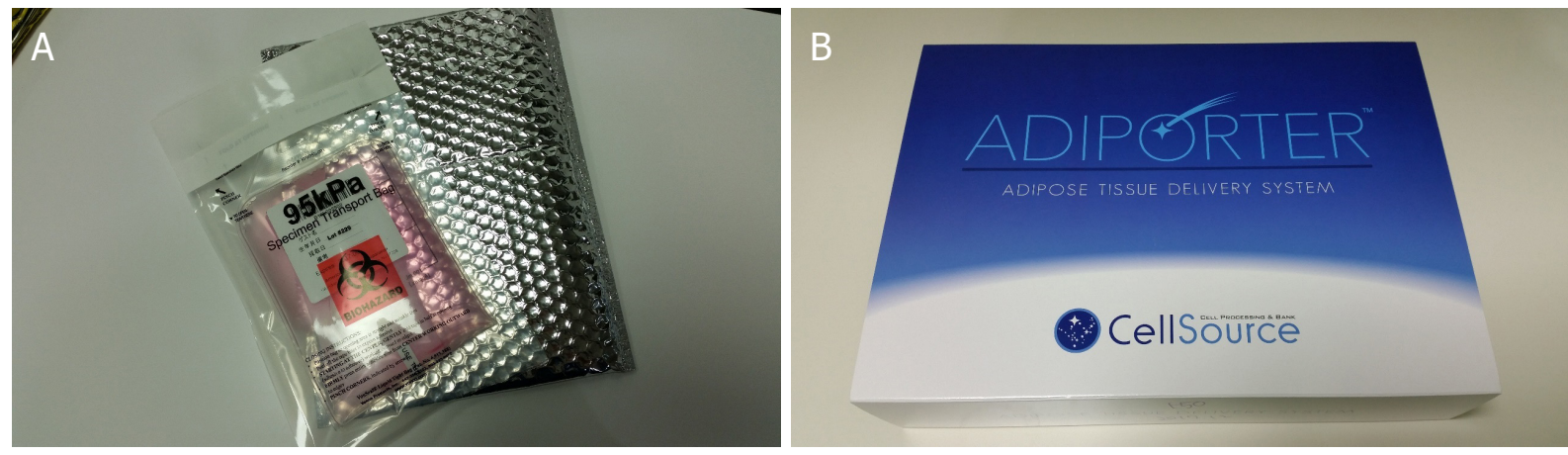

Figure 2. Kit for transportation. A: FB-bag (CellSource Co., Ltd., Tokyo, Japan), which contains an adipose tissue transport medium; B: Adiporter (CellSource Co., Ltd., Tokyo, Japan), which is the box in which the fat is sent to the cell processing center company in a refrigerated state (below $10^{\circ} \mathrm{C}$ ). This figure is used with permission from Ohashi et al. ${ }^{[18]}$ published in Plast Reconstr Surg Glob Open

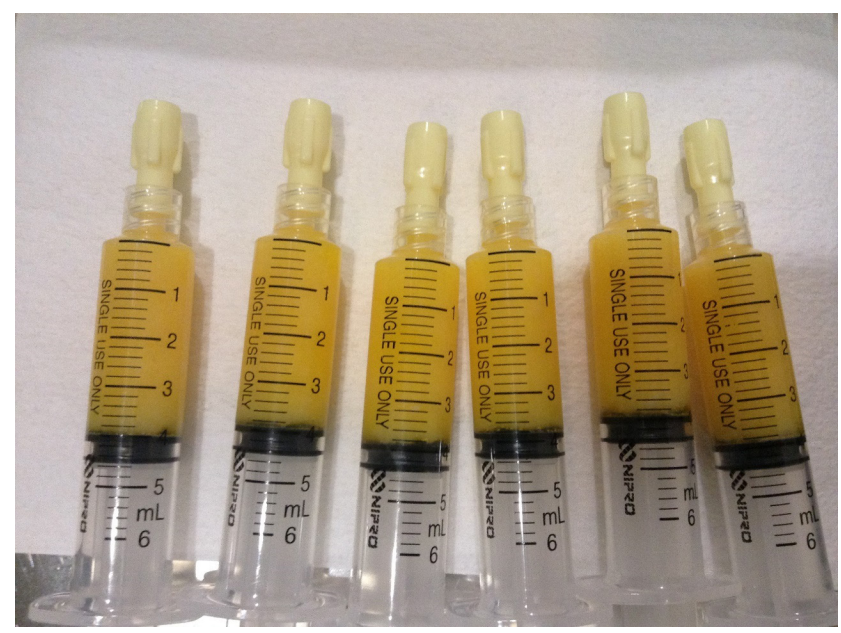

Figure 3. Thawed cryopreserved fat. This photograph was taken at our clinic. The material looks like fresh fat, and there is almost no oil in those syringes. This figure is used with permission from Ohashi et al. ${ }^{[18]}$ published in Plast Reconstr Surg Glob Open

$-80^{\circ} \mathrm{C}$. They are then transferred to liquid nitrogen and stored at $-196^{\circ} \mathrm{C}$.

Using this process, we can store many syringes of patients' fat after single harvesting sessions.

\section{Return of fat}

When we want to use cryopreserved fat, we use an Internet web-ordering service from the CellSource CPC to place an order. After the CPC receives the order, the patient's cryopreserved fat is thawed rapidly $\left(37^{\circ} \mathrm{C}\right)$ and the cryoprotectant liquid is washed out. The CPC sends back that fat to our clinic in a refrigerated state (below $10^{\circ} \mathrm{C}$ ) [Figure 3].

\section{Injection of thawed cryopreserved fat}

The thawed fat must be injected within 48 hours of receiving it. We follow the "Coleman technique" for volume augmentation, and use the "nanofat (emulsified fat) technique" for skin rejuvenation. The fat is usually used at multiple injection sites. For example, the first injection of cryopreserved fat may be used for breast augmentation and the second injection for forehead volume augmentation and/or scar treatment. We may use the cryopreserved fat many times if the supply lasts. Therefore, we can inject each patients many times easily. 
Table 2. Characteristics of patients who received their cryopreserved fat $(n=216)$

\begin{tabular}{ll}
\hline Duration & Aug 2015 Dec 2018 \\
Sex & Male 14 Female 202 \\
Age (years) & $19-79(40.8 \pm 11.5)$ \\
Height $(\mathrm{cm})$ & $147.5-188(160.0 \pm 5.9)$ \\
Weight $(\mathrm{kg})$ & $38.5-90.7(52.1 \pm 8.1)$ \\
Body mass index $\left(\mathrm{kg} / \mathrm{m}^{2}\right)$ & $15.9-31.6(20.3 \pm 2.5)$ \\
\hline
\end{tabular}

Table 3. Number of patients with different injection times using cryopreserved fat from one harvesting

\begin{tabular}{ll}
\hline 1 time & 216 patients \\
2 times & 59 patients \\
3 times & 25 patients \\
4 times & 10 patients \\
5 times & 1 patient \\
6 times & 1 patient \\
\hline
\end{tabular}

Table 4. The ways cryopreserved fat was used

\begin{tabular}{ll}
\hline Volume augmentation only - 169 cases & \\
Facial rejuvenation & 143 cases \\
Body augmentation & 26 cases \\
Revitalization/fertilization only - 98 cases & 11 cases \\
Improve skin condition only & 55 cases \\
Scar only & 32 cases \\
Improve skin condition and for scar & 87 cases \\
$\quad$ Volume augmentation + revitalization/fertilization & \\
(Treatment for scar \& fibrous tissue with/without PALF) & 53 cases \\
$\quad$ Face (Injury scar, revision of liposuction, acne scar) & 19 cases \\
$\quad$ Revision of liposuction (thigh, abdomen) & 5 cases \\
$\quad$ Revision of SIEF & 10 cases \\
$\quad$ Incision scar (IMF, nipple, axillar) & \\
\hline &
\end{tabular}

\section{Follow-up of patients}

We followed-up each patient after at one month and 3-6 months after the first injection using fresh fat, and also at one month and 3-6 months after repeat injections using thawed cryopreserved fat.

\section{Comparison of stromal vascular fraction}

We compared the amount of stromal vascular fraction (SVF) in fresh fat before sending it to the CPC with the SVF of thawed cryopreserved fat. SVF was digested by collagenase (Wako Pure Chemical, Osaka, Japan). Cell count and viability of SVF were performed by KUNA-STEAM Automated Fluorescence Cell Counter (Logos Biosystems, South Korea).

\section{RESULTS}

Of the 490 patients who underwent fat harvesting in our clinic, 216 patients ( 312 cases) received fat grafting with cryopreserved fat. The characteristics of those patients are shown in Table 2. The number of patients who received a varying number of injections from one harvesting session is shown in Table 3. The ways of using cryopreserved fat are shown in Table 4. The injected volume of cryopreserved fat was from 0.2 to $24.0 \mathrm{~mL}$ for the face and from 4.0 to $100.0 \mathrm{~mL}$ for the body.

There were no severe complications in any patients. Mild complications occurred in 5 patients (2.3\%), all of which were temporary pigmentation [Table 5]. 
Table 5. Complication

\begin{tabular}{ll}
\hline $\begin{array}{l}\text { Severe or moderate complication } \\
\text { Mild complication }\end{array}$ & $\begin{array}{l}\text { 0 patients }(0 \%) \\
5 \text { patients }(1.9 \%)\end{array}$ \\
\hline${ }^{\star}$ For example, infection and fat necrosis; ${ }^{\star \star}$ only temporary pigmentations \\
(inflammatory pigmentation and scars from needling)
\end{tabular}

Table 6. Volume change of fat after cryopreservation

\begin{tabular}{lll}
\hline & Not centrifuged & Centrifuged \\
Sent volume & $169 \mathrm{~mL} \pm 72.7 \mathrm{~mL}$ & $143 \mathrm{~mL} \pm 67.9 \mathrm{~mL}$ \\
Returned volume & $59 \mathrm{~mL} \pm 29.2 \mathrm{~mL}$ & $76 \mathrm{~mL} \pm 43.9 \mathrm{~mL}$ \\
$\%$ volume & $34.4 \% \pm 5.5 \%$ & $51.3 \% \pm 9.8 \%$ \\
\hline
\end{tabular}

Not centrifuged: only gravity; centrifuged: usually $700 \sim 1200 \mathrm{~g}, 3 \mathrm{~min}$. Table 6 is used with permission from Ohashi et al. ${ }^{[18]}$ published in Plast Reconstr Surg Glob Open

A comparison of sent and returned fat volumes showed that fat volume decreased $34.4 \%$ if it was not centrifuged before being sent, and decreased $51.3 \%$ if centrifuged before sending [Table 6].

SVF in fresh fat was $7.1 \times 10^{5} / \mathrm{mL}$ (before sending) and $14.8 \times 10^{5} / \mathrm{mL}$ in thawed cryopreserved fat (returned fat) $(n=5)$. These amounts reflect the amounts of $\mathrm{SVF} / \mathrm{mL}$ that were concentrated from cryopreserved fat as compared to fresh fat.

\section{We show some cases below}

Case 1: facial rejuvenation using cryopreserved fat [Figure 4]

A 46 y.o. patient disliked her bony face and wanted to look younger. She did not want to undergo painful harvesting many times. Therefore, we planned serial injections after one harvesting session followed by the cryopreservation of her fat. She received facial rejuvenation surgery (first operation) involving fat grafting to her forehead $(20.0 \mathrm{~mL})$, cheeks $(8.0 \mathrm{~mL}$ each), and lips $(1.5 \mathrm{~mL}$ each) with thread lift (Silhouette Soft; Sinclair Pharma, London, UK) using the bidirectional floating method for her sagging cheeks, and her residual fat was sent for cryopreservation. After her first operation, she received two more fat grafting procedures using her cryopreserved fat within one year (three and six months after her first operation). She looked younger and healthy after these operations.

\section{Case 2: facial rejuvenation using cryopreserved fat [Figure 5]}

A 47 y.o. patient hated her bony forehead and complained of looking older than her real age. Her first operation involved facial fat grafting to her forehead $(22.0 \mathrm{~mL})$, malar area $(3.0 \mathrm{~mL}$ each), cheeks $(5 \mathrm{~mL}$ each), upper and lower eyelids (1.0 mL each, and $1.5 \mathrm{~mL}$ each, respectively) and chin $(2.3 \mathrm{~mL})$ with lower orbital fat removal. After her first operation, she received fat grafting using her cryopreserved fat two more times within two years (6 and 18 months after first operation). Postoperative photographs [Figure 5] are one year after her last fat grafting procedure using cryopreserved fat (3.5 years after her first injection), where she appears more youthful than she did prior to her first operation.

\section{Case 3: repeat rigottomy (needling) using cryopreserved fat [Figure 6]}

A 41 y.o. patient had undergone breast implant removal and simultaneous fat grafting (SIEF) ${ }^{[19,20]}$. However, three months after the operation, her right breast became deformed due to capsule contracture. Therefore, we performed a rigottomy (percutaneous aponeurotomy) with fat grafting using fresh fat followed by serial injections using cryopreserved residual fat. After receiving five total rigottomies with fat grafting (two with fresh fat, three with cryopreserved fat), her breasts developed a nearly natural appearance. 

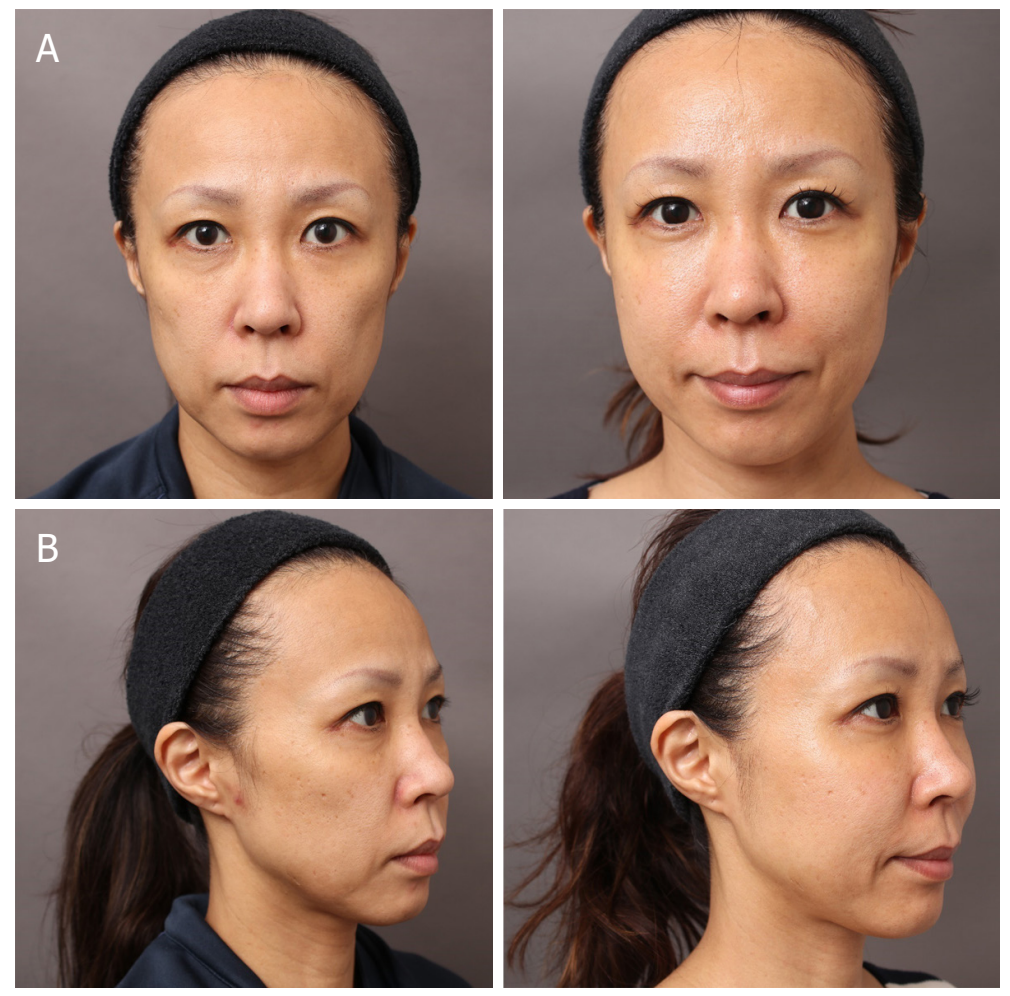

Figure 4. case 1: facial rejuvenation using her cryopreserved fat. A: front view B: diagonal view. (left) Preoperative. (right) 6 months after second cryopreserved fat grafting. This figure is used with permission from Ohashi et al. ${ }^{[18]}$ published in Plast Reconstr Surg Glob
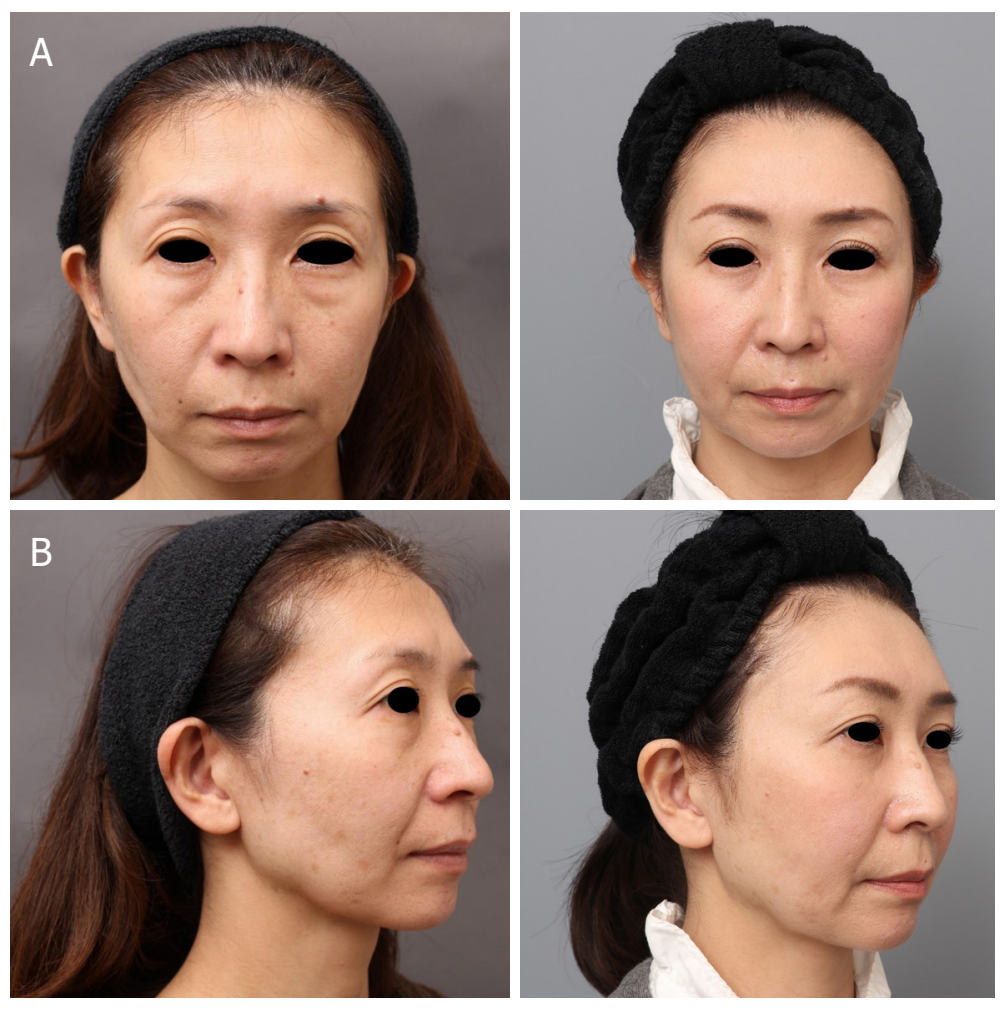

Figure 5. Case 2: facial rejuvenation using her cryopreserved fat. A: front view B: diagonal view. (left) Preoperative. (right) 3.5 years after her first injection. This figure is used with permission from Ohashi published in Clin Plast Surg ${ }^{[16]}$ 

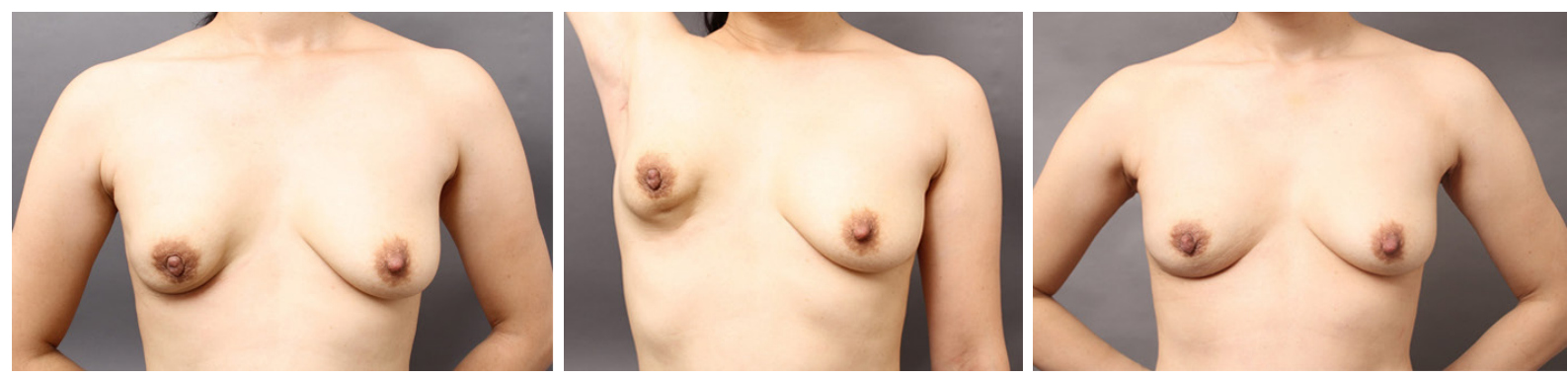

Figure 6. Csae 3: repeat rigottomy (needling) using cryopreserved fat. (left) after 3 months postoperative follow-up. Her right side residual capsule was greatly shrunken; (middle) her appearance when she holds up her right arm; (right) after receiving a total of five rigottomies with fat grafting (two with fresh fat, three with cryopreserved fat). This figure is used with permission from Ohashi et al. ${ }^{[18]}$ published in Plast Reconstr Surg Glob Open
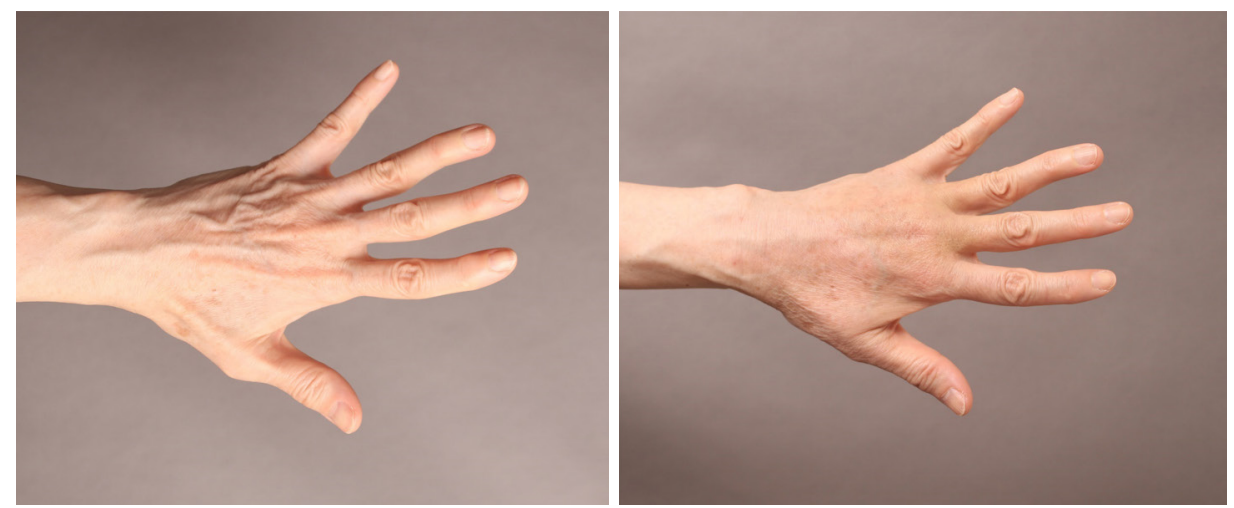

Figure 7. Case 4: hand rejuvenation using residual fat. (left) Before operation. (right) After injection of cryopreserved fat, veins covered with fat and unremarkable. This figure is used with permission from Ohashi et al. ${ }^{[1]}$ published in Plast Reconstr Surg Glob Open

Case 4: hand rejuvenation using residual fat [Figure 7]

A 65 y.o. woman received fat grafting for breast augmentation and requested her cryopreserved residual fat be used as well. Four months after the first operation, she received fat grafting in her hands $(16.0 \mathrm{~mL}$ for each hand) for hand rejuvenation without any additional harvesting needed.

\section{DISCUSSION}

Fat grafting is a major procedure for volume augmentation of areas such as the breasts, buttocks, and face. It has become clear that there are other merits of fat grafting including but not limited to skin rejuvenation, improve of fibrous scars, burn relief, alleviation of scleroderma symptoms, and healing of radiation damage. This is due to the revitalization/fertilization and regenerative effects of fat ${ }^{[4,7,21,22]}$.

However, one of the biggest demerits of fat grafting is the unpredictable nature of results involving varying maintenance rates for volume augmentation and the unpredictable degree of revitalization/fertilization and regeneration effects.

Due to varying effects, we often administer repeat injections to achieve satisfactory results. But repeat harvesting of fresh fat has detrimental impacts on patients with regard to pain and high costs. Therefore, it is in the interest to both aesthetic/plastic surgeons and patients to be able to preserve and use cryopreserved fat.

There are concerns regarding the viability of cryopreserved fat ${ }^{[23,24]}$. Many authors have recently suggested that slow cooling and fast thawing with cryoprotective agents may improve the viability of stored fat to a degree comparable to that of fresh fat ${ }^{[25-27]}$. 
Improper cryopreservation techniques may compromise fat viability; however, with adequate cryopreservation techniques such as slow cooling and fast thawing, preservation at $-196{ }^{\circ} \mathrm{C}$ (below $-85{ }^{\circ} \mathrm{C}$ ) and the addition of cryoprotective agents foster high fat viability ${ }^{[27-29]}$.

We trust the CPC (CellSource Co. in Tokyo) to use proper cryopreservation techniques. Our responsibilities, therefore, only include packaging and sending residual fat. To use the cryopreserved fat, we then recall the fat [refer to Figure 1]. This ordering system allows small clinics to use cryopreserved fat without needing high-cost cell processing facilities on site. This makes it easier for clinics to start using cryopreserved fat safely while ensuring the stable quality of the fat. Having specialists conduct cell processing also benefits patients by preserving the quality of their fat for repeat injections.

Regarding volume and SVF count of cryopreserved fat, our results showed that the volume of fat decreased after cryopreservation; however, the amount of SVF per $\mathrm{mL}$ increased. This may be attributed to the fact that SVF (and adipose-derived stromal cells) is stronger than normal adipocytes in response to stress from factors such as ischemia, mechanical damage (during transportation), and cryopreservation ${ }^{[6]}$. According to our results, cryopreserved fat is very useful for rejuvenation and fertilization/revitalization.

Lastly, our cases indicated that cryopreserved fat has comparable viability as fresh fat; however, further studies are needed to compare the retention rate and regeneration effects of fresh and cryopreserved fat in a pathological study.

In summary, we did not experience any severe complications in any of our 216 patients over three and half years. Our results indicated that fat grafting with cryopreserved fat closely mimics that with fresh fat, making cryopreserved fat a safe and useful source for repeat fat grafting injections.

\section{DECLARATIONS}

\section{Acknowledgments}

We thank Hidato Kaneshima, MD, PhD, Satoshi Tsunoda, and Syunsuke Tazumi from CellSource Co., Ltd. for providing methods for cryopreservation and thawing.

\section{Authors' contributions}

The author contributed solely to the article.

\section{Availability of data and materials}

Not applicable.

\section{Financial support and sponsorship}

None.

\section{Conflicts of interest}

The author declared that there are no conflicts of interest.

\section{Ethical approval and consent to participate}

In Japan, the Regenerative Medicine Safety Act came into effect as of November 25, 2014 under an institutional framework for promoting the implementation of regenerative medicine. This act, which covers clinical research and private practice, stipulates three risk-dependent standards and the procedures for notification of plans for regenerative medicine as well as the standards of cell culture and processing facilities and the licensing procedures to ensure the safety of regenerative medicine. 


\section{Consent for publication}

The author obtained consent for publication from all patients we show in this article.

\section{Copyright}

(c) The Author(s) 2020.

\section{REFERENCES}

1. Coleman SR. Structural fat grafts: the ideal filler? Clin Plast Surg 2001;28:111-9.

2. Coleman SR. Structural fat grafting: more than a permanent filler. Plast Reconstr Surg 2006;118:108S-20S.

3. Khouri RK, Rigotti G, Cardoso E, Khouri RK Jr, Biggs TM. Megavolume autologous fat transfer: part I. Theory and principles. Plast Reconstr Surg 2014;133:550-7.

4. Khouri RK, Smit JM, Cardoso E, Pallua N, Lantieri L, et al. Percutaneous aponeurotomy and lipofilling: A regenerative alternative to flap reconstruction? Plast Reconstr Surg 2013;132:1280-90.

5. Tonnard P, Verpaele A, Peeters G, Hamdi M, Cornelissen M, et al. Nanofat grafting: basic research and clinical applications. Plast Reconstr Surg 2013;132:1017-26.

6. Mashiko T, Wu SH, Feng J, Kanayama K, Kinoshita K, et al. Mechanical micronization of lipoaspirates: Squeeze and emulsification techniques. Plast Reconstr Surg 2017;139:79-90.

7. Sautereau N, Daumas A, Truillet R, Jouve E, Magalon J, et al. Efficacy of autologous microfat graft on facial handicap in systemic sclerosis patients. Plast Reconstr Surg Glob Open 2016;4:e660.

8. Losken A, Pinell XA, Sikoro K, Yezhelyev MV, Anderson E, et al. Autologous fat grafting in secondary breast reconstruction. Ann Plast Surg 2011;66:518-22.

9. Gatti JE. Permanent lip augmentation with serial fat grafting. Ann Plast Surg 1999;42:376-80.

10. Kim HY, Jung BK, Lew DH, Lee DW. Autologous fat graft in the reconstructed breast: Fat absorption rate and safety based on sonographic identification. Arch Plast Surg 2014;41:740-7.

11. Pu LLQ, Coleman SR, Cui X, Ferguson REH Jr, Vasconez HC. Cryopreservation of autologous fat grafts harvested with the Coleman technique. Ann Plast Surg 2010;64:333-7.

12. Gir P, Brown SA, Oni G, Kashefi N, Mojallal A, et al. Fat grafting: evidence-based review on autologous fat harvesting, processing, reinjection, and storage. Plast Reconstr Surg 2012;130:249-58.

13. Pu LLQ, Cui X, Fink BF, Gao D, Vasconez HC. Adipose aspirates as a source for human processed lipoaspirate cells after optimal cryopreservation. Plast Reconstr Surg 2006;117:1845-50.

14. Ibrahiem SMS, Farouk A, Salem IM. Facial rejuvenation: serial fat graft transfer. Alexandria J Med 2016;52:371-6.

15. Butterwick KJ, Bevin AA, Iyer S. Fat transplantation using fresh versus frozen fat: a side-by-side two-hand comparison pilot study. Dermatol Surg 2006;32:640-4

16. Ohashi M. Fat grafting for facial rejuvenation with cryopreserved fat grafts. Clin Plast Surg 2020;47:63-71.

17. Geissler PJ, Davis K, Roostaeian J, Unger J, Huang J, et al. Improving fat transfer viability: the role of aging, body mass index, and harvest site. Plast Reconstr Surg 2014;134:227-32.

18. Ohashi M, Chiba A, Nakai H. Serial injections of cryopreserved fat at $-196 \square$ for tissue rejuvenation, scar treatment, and volume augmentation. Plast Reconstr Surg Glob Open 2018;6:e1742.

19. Del Vecchio DA. "SIEF" - simultaneous implant exchange with fat: a new option in revision breast implant surgery. Plast Reconstr Surg 2012;130:1187.

20. Ohashi M, Yamakawa M, Chiba A, Nagano H, Nakai H. Our experience with 131 cases of simultaneous breast implant exchange with fat (SIEF). Plast Reconstr Surg Glob Open 2016;4:e691.

21. Khouri RK Jr, Khouri RK. Current clinical applications of fat grafting. Plast Reconstr Surg 2017;140:466e-86e.

22. Rigotti G, Marchi A, Galiè M, Baroni G, Benati D, et al. Clinical treatment of radiotherapy tissue damage by lipoaspirate transplant: a healing process mediated by adipose-derived adult stem cells. Plast Reconstr Surg 2007;119:1409-22.

23. Pu LLQ, Cui X, Fink BF, Cibull ML, Gao D. Long-term preservation of adipose aspirates after conventional lipoplasty. Aesthet Surg J 2004;24:536-41.

24. Wolter TP, von Heimburg D, Stoffels I, Groeger A, Pallua N. Cryopreservation of mature human adipocytes: In vitro measurement of viability. Ann Plast Surg 2005;55:408-13.

25. Jeon IK, Lee H, Shin JY, Oh SH. Cryopreserved autologous fat injections as a filler agent for facial augmentation: are they still safe? Yosei Med J 2014;55:280-1.

26. MacRae JW, Tholpady SS, Ogle RC, Morgan RF. Ex vivo fat graft preservation: effects and implications of cryopreservation. Ann Plast Surg 2004;52:281-2.

27. Pu LL. Cryopreservation of adipose tissue. Organogenesis 2009;5:138-42.

28. Hwang SM, Lee JS, Kim HD, Jung YH, Kim HI. Comparison of the viability of cryopreserved fat tissue in accordance with the thawing temperature. Arch Plast Surg 2015;42:143-9.

29. Shu Z, Gao D, Pu LLQ. Update on cryopreservation of adipose tissue and adipose-derived stem cells. Clin Plast Surg 2015;42:209-18 